\title{
Stimulating retail sales and upholding customer value
}

Received (in revised form): 18 January 2007

\section{Rajagopal}

is Full Professor in the Department of Marketing at Monterrey Institute of Technology and Higher Education (ITESM), Mexico City Campus and Fellow of the Royal Society for Encouragement of Arts, Manufacture and Commerce, London. He holds doctoral degree from Ravishankar University, India and has been conferred the membership (level-II) of Mexican National System of Researchers. He teaches various topics of marketing in the under-graduate, post-graduate and doctoral programmes of the Institute. Dr Rajagopal was associated with University of Birmingham, UK and held key positions in many premier management institutes in India including Administrative Staff College of India.

\begin{abstract}
Consumer responses to clearance sales, both in terms of consumer satisfaction with the decision process and subsequent store choice behaviour, are explored in the paper through controlled experiments conducted involving clearance sales in a consumer choice and decision satisfaction context. The results suggest that consumer response to clearance sales is driven to a large extent by two factors: the effect of a clearance sale on the available options of goods and the degree of store loyalty. Response to a clearance sale was found to be a function of two primary forces - the degree to which a consumer was personally committed to the discount sales alternative, and changes in the difficulty of making a decision due to limitation of buying options. Overall, the discussion of results of the two studies presented in the paper demonstrates that consumer response to clearance sales, both in terms of decision satisfaction levels and observed store-loyalty behaviour, are strongly influenced by the variables of price sensitivity, attractiveness of products, store loyalty and perceived value on available brands.
\end{abstract}

\section{Keywords:}

clearance sales, consumer behaviour, retail promotion, store loyalty, buying decision, customer value

Journal of Retail and Leisure Property (2007) 6, 117-135. doi:10.1057/palgrave.rlp.5100054

Rajagopal

Department of Marketing Business Division

Monterrey Institute of Technology and Higher Education ITESM, 222, Calle del Puente Tlalpan, Mexico DF 14380

Tel: +525554832251

Fax: +525554831341

E-mail: rajagopal@itesm.mx

\section{INTRODUCTION}

This study analyses the business setting of a firm in which a clearance sale stimulates the response from consumers in a cyclical seasonality, viz. summer and post-Christmas winter-spring clearances offered by the self-service retail stores. Theoretically, it is suggested that consumers will react favourably to a clearance sale; however, customer values go 
negative for the high-technology and high use value products in proportion to the consumer's individual behaviour to the discount sales option. It may be argued that individual consumer behaviour to a buying option is a function of preference for the option, whether it is a considered option or any choice constraint is personally directed. The consumer response is also affected by search associated with making a decision on a clearance sale. Consequently, when a clearance sale leads to an increase in decision difficulty consumers will respond more negatively or indifferently, while if the clearance sale leads to a decrease in difficulty and offers a wider product line, the response to a clearance sale can be positive. The results across a series of micro-studies discussed in this paper evidence that consumer response to clearance sales is positively related to the importance of price advantage while is inversely related to the change in decision difficulty or intimidation of search costs. The studies show that consumers respond to clearance sales by changing their evaluations of satisfaction with the decision process and by changing their store-loyalty or brand-loyalty behaviour, but not by changing their satisfaction with the consumption of the product ultimately selected.

The implication of consumer response to clearance sales is substantial, particularly given the prevalence of clearance sales with predetermined cyclicality in self-service stores. ${ }^{1-3}$ Clearance sale levels of $25-50$ per cent in retail settings have found to be the predetermined expectation of the consumers, rather than an exceptional offer in the retail self-service stores. ${ }^{4}$ More recently, clearance sales have become a major problem for online merchants, due to both traditional forecasting problems and poor links between their inventory systems and their websites. ${ }^{5}$ The series of micro-studies presented in the paper seeks to develop estimates of the potential cost of clearance sales, both in terms of consumers' decision satisfaction levels and in terms of the impact of a clearance sale on actual store-loyalty behaviour.

The following section examines the research contributions on two of the factors that are most critical in understanding and predicting consumer response to clearance sales. This paper discusses the results of two experiments based on a framework for understanding consumer response to clearance sales and a set of hypotheses is developed accordingly. Each study attempts to demonstrate varying consumer response to clearance sales as well as to identify the conditions under which clearance sales might increase versus decrease consumers' evaluations of the decision experience. The final section of the paper wraps up the overall findings, discusses the implications of these findings for researchers and identifies opportunities for future research.

\section{RESPONSE BEHAVIOUR TO CLEARANCE SALES}

The retail self-service stores that largely operate in chain are based on the rationale of touch, feel and pick, which provides consumers a wide range of options to make buying decisions. The in-stores promotions and do it yourself (DIY) opportunities constitute the major motivation for the buyers and also support their decision-making process. Motivational 
forces are commonly accepted to have a key influencing role in the explanation of shopping behaviour. Personal shopping motives, values and perceived shopping alternatives are often considered independent inputs into a choice model. We argue that shopping motives influence the perception of retail store attributes as well as the attitude towards retail stores. ${ }^{6}$ In retail self-service stores where consumers exercise in-store brand options, both service and merchandise quality exert significant influence on store performance, measured by sales growth and customer growth, and their impact is mediated by customer satisfaction. The liberal environment of the self-service stores for merchandise decisions, service quality and learning about competitive brands are the major attributes of retail self-service stores. ${ }^{7}$ The retail self-service stores offer an environment of three distinct dimensions of emotions, for example, pleasantness, arousal and dominance. The retail self-service stores operate on a market size effect and a price cutting effect. ${ }^{8}$

As the retail self-service stores display a wide range of multi-brand products, the consumers enjoy higher chance of finding preferred products (a market size effect). On the other hand, concentration of stores leads to fiercer price competition (a price cutting effect). A number of researchers have dealt indirectly with consumer response to clearance sales. Pratkanis and Farquhar' studied the impact of 'phantom' alternatives (unavailable options) on consumer choice probabilities and proposed a context-dependent model of choice. Whereas most traditional models of individual consumer choice have assumed that the addition of an unavailable alternative to a choice set will have no impact on the ratios of choice probabilities among the original alternatives, ${ }^{10}$ Farquhar and Pratkanis demonstrate cases in which this assumption is violated. Merrilees and Fam ${ }^{11}$ observed that the clearing sale is a dominant part of modern retailing worldwide. As a marketing tool, it has always had an important and legitimate role in creating consumer excitement and in clearing surplus or obsolete stock. In recent years, however, the sale has become ubiquitous and pervasive and, apparently, used to excess, threatening profit margins and even the survival of certain retailers who rely too much on them. There are some critical issues associated to the price-sensitive consumer behaviour, whether customers are equally price sensitive while purchasing products for functional (eg purchasing frozen vegetables, toiletries or paper towels) versus hedonic (eg purchasing a high-technology computer or a video camera) consumption situations and whether perceived value derived during consuming the product influences price sensitivity. It may also be stated that higher price volatility makes consumers more sensitive to gains and less sensitive to losses, while intense price promotion by competing brands makes consumers more sensitive to losses but does not influence consumers' sensitivity to gains. ${ }^{12}$

Research on deferred decision making presents an interesting counter to studies investigating response to the removal of an option to choose. Works by both Tversky and Shafir ${ }^{13}$ and Dhar ${ }^{14}$ describes situations in which people may wish to add an alternative to a choice set. The prospect theory laid by Tversky and Khanman ${ }^{15}$ proposes that the intensity of gains plays strategic role in value enhancement as $G_{x t}=g_{p t}\left(\partial_{x} / \partial_{p}\right)$. In this equation, $G_{x t}$ offers competitive advantage in a given time $t$ and the 
promotional strategies are implemented to enhance the customer values in reference to product specific gains as expressed by $\left(g_{p t}\right)$. In the above expression $x$ represents the volume of goods while $p$ denotes the price of goods. Tversky and Shafir ${ }^{13}$ argue and demonstrate that as the conflict between items in a choice set increases, people become more likely to defer making a decision and, in some cases, explicitly request that additional options be added to the set. Similarly, Dhar ${ }^{14}$ found that consumers were more likely to defer choice or select a no-choice option under conditions of increased conflict between choice alternatives. Assuming a simple probabilistic model of consumer choice, ${ }^{16}$ the value associated with the option to choose should be a function of both the utilities associated with the choice category. As both the importance of the choice category and the preference for an alternative outlet increase, the value associated with the option to choose a particular alternative becomes critical.

Research on consumer reaction to price has been largely confined to examining consumers' price information search, evaluation of price alternatives and individual purchase behaviours without regard to situational influences. At the same time, consumption has often been dichotomised in terms of its functional-hedonic nature and closely associated with the level of satisfaction leading to determine the customer value influence. ${ }^{17}$ As the new products are introduced, a firm may routinely pass these costs on to consumers resulting into high prices. A less obvious strategy in a competitive situation may be, however, to maintain price, in order to drive the new product in the market with more emphasis on quality, brand name, post-sales services and customer relations management as nonprice factors. In many ways, such strategies of a firm with the new products may drive the consumer behaviour towards being sensitive to the price increase when it comes to making a buying decision. Some of the marketplace and experimental studies show that consumers are more sensitive to changes in price than to innovation and new products introduced by the firm. ${ }^{18}$ As discussed above, clearance sales act as stimulus to consumers who are likely to elicit a positive response. Further, it is predicted that the magnitude of this positive response will be proportional to the value of an option to select the discount sales alternative. Hence, it may be hypothesised as

H1: Consumers offered with a clearance sale of an attractive alternative will be more satisfied and will hold higher store-loyalty rates than similar consumers without being offered any clearance sales.

There are many new ways through which marketers can determine the success of their promotions in store, and discovers the types of supermarket promotions that work. Innovative promotions to attract young customers towards fashion goods confirm the promotional value of free toys with cereals, especially for younger children. A study refers that the PromoPull evaluation tool was developed to measure the promotional pull, that is, the share of buyers who bought the product due to the promotion. ${ }^{19}$ It may be understood that as the attractiveness of a choice 
option increases, negative response of consumers buying in clearance sales will decrease. Exercising choice options in clearance sales, however, will be a function of two factors that are related to the process of comparing a brand-based product alternatives and price advantage directed at the particular category of products. Some research studies discuss the long-term value concepts of loyal customers and advocate the models of building customer value through traditional relationship marketing. Most importantly, these are expected to raise their spending and association with the products and services of the company with increasing levels of satisfactions that attribute to values of customers. ${ }^{20}$ In the most optimistic settings, such value creation is observed to generate new customers for new products in view of the customer relationship and value management strategies of the firm. ${ }^{21}$ Epstein analyses the case of clearance sales in a store selling than selling one commodity at a discounted price. ${ }^{22}$ Conditions and rules of thumb are shown in which it is optimal to increase the price of one product while decreasing the price of another. A linear demand model and a numerical example are presented, showing that the price of one product decreases while the price of the other product may increase or decrease in different periods. The following hypothesis is therefore framed:

H2: The intention of the consumers towards buying the products in the clearance sales depends on the attractiveness of the offer, store loyalty and the level of perceived conflicts in decision process.

In general, consumers believe that they will be able to choose freely in the clearance sales offer and that is perceived as behaviourally directed advantages, which is much more likely to lead to high levels of experienced reactance. It has been argued that clearance sales attract the secondary buyers like parents, as children were allowed to freely choose toys more than the expected volume to take home. ${ }^{23}$ Half the participants were allowed to choose which of the two toys they wanted to take home. Clearance sale announcement has a much greater personal direction than a loyalty buying. In addition, the moderation role of fear of losing face (or embarrassment) also acts a driving factor in rushing towards the clearance sale. ${ }^{24}$ The fear of losing face significantly moderates the relationship between in-store display and clearance sale. In the similar context, another research highlights that only price discount promotions proved to be statistically significant on a consumer's reported buying behaviour. In the process of making buying decisions in the clearance sales, the purchase acceleration and product trial are found to be the two most influential variables related to a discount. ${ }^{25}$ Thus, the hypothesis may be framed as

H3: The clearance sale offer increases the influence on individually directed decision that would manifest in higher satisfaction levels in the short run against the standard disposition of consumers towards buying unfamiliar brands. 
The magnitude of consumer response to clearance sales is weighed in two ways - evaluative and behavioural. First, consumer satisfaction with the decision process leading to the expected level of satisfaction is measured, which may be expressed as one of a number of cognitive and affective responses that may result from a clearance sale. The basic concept of satisfaction with consumers' experience in arriving at a purchase decision has been introduced in a study of consumer-durable purchases, which argued that while substantial research had been performed on consumer satisfaction with the use or consumption of a good, little research had addressed consumers' experiences of learning about brands and product categories or deciding which option to purchase. ${ }^{26}$ The results of the study conducted by Oakley reveals that greater success in sales of fashion goods sales is significantly associated with a more ambitious and speedier launch clearance of older inventory to allow the inflow of new fashion goods effectively. ${ }^{27}$ The retail sales performance and the customer value approach are conceptually and methodically analogous. The satisfaction is the customer's perception of the value received in a transaction or relationship, and it helps in making re-patronage decisions on the basis of their predictions concerning the value of a future product. It may be thus stated that the customer value paradigm is contemporary, which includes many elements of the customer satisfaction paradigm and is being more widely adopted and deployed by the firms. ${ }^{28,29}$ Arguments on the issues of consumers' decision satisfaction have been further stretched by the researchers, demonstrating that decision satisfaction is a significant contributor to consumers' overall satisfaction judgments and is conceptually distinct from satisfaction with the consumption of a good. It has been observed in various factor analyses that the underlying dimensions of decision and consumption satisfaction are separate and identifiable. ${ }^{30}$

\section{THEORETICAL CONSTRUCT}

Fashion goods including apparel have a quick shelf turnover, at relatively low cost and quick buying decisions of consumers. The rate of change within the fashion goods continues apace, particularly in the area of innovation and value additions. A firm may combine innovation and technologies in the new products to create customer value and competitive gains. The fashion apparel in the retail market segments are largely attracted by the innovations in product attributes and packaging besides the price sensitivity. It has been observed that buying decision with probability to try the new product are systematically moderated by elements of the marketing strategy associated with the new product and by growing fashion attributes. ${ }^{31}$ Under such market conditions, the customer value is also driven by the satisfaction that is offered by the substitutes. Often, the firms face competition within their product line due to implementation of product overlap strategy, which generates conflicting customer values. When a firm introduces a high-value product derived out of the research and development efforts, it prescribes the use value for it; however, the perceived use value for the product may not match with the prescribed use value tagged to the product by the firm. 
Such uncertainty may cause low performance of product in terms of buying preferences.

A firm may introduce the fashion apparel in clearance sales in the given market $M_{t}^{\left(i_{1}+i_{2}+i_{3}+\ldots i_{n}\right) j}$ in terms of product attributes $\left(i_{1}\right)$, distribution $\left(i_{2}\right)$, promotion $\left(i_{3}\right)$ and other related factors $\left(\ldots i_{n}\right)$ related with gaining competitive advantage in a given time $(t)$ in the $j$ th market. Let us assume that $s$ is the estimated market coverage for the new product, the customer value $\left(V_{n p}\right)$ may be initially positive and high, resulting into deeper market penetration (with $s$ increasing). This may be described as:

$$
M_{t}^{\left(i_{1}+i_{2}+i_{3}+\ldots\right) j}=\frac{\partial s}{\partial t}=k
$$

$V_{n p} \leqslant \partial v / \partial t$ may, however, become negative following product competition within the product line due to the product overlap strategy of the firm of fashion apparel of unfamiliar brands. In the above equation, volume of buying is represented by $\partial v$ in a given time $t$. To augment the customer value and enhance market coverage for the new products in the potential markets, the firm may optimise the product line $[s]_{p t}^{i, h}$ by pruning the slow-moving products in the jth chain in $h$ market in order to reposition them in new market. Hence,

$$
[s]_{P t}^{j, h}=\left[\frac{\partial v}{\partial t}\right]^{j, h}+\Pi\{V(x, t, q, p)\}
$$

In the above equation, perceived customer value $(V)$ is a function of price $(p)$ and nonprice factors including quality $(q)$ and volume $(x)$ in a given time $t$. Hence, to enhance the market coverage for fashion apparel with enhancing the customer value for the new and unfamiliar brands of the firm, the strategy may be described as:

$$
s=\int\left[k+\{s\}_{P t}^{j, h}\right] \partial t+\beta^{t} R
$$

where $s$ is the market coverage of the new product, $k$ is the investment on market functions derived in a given time (equation (1)) and $R$ is the referral factor influencing the customer values with an advantage factor coefficient $\beta$ in time $t$. The products constituting the optimal product line of the firm in a given time is represented by $P_{t}$ in the above equation. The firm may measure the customer value shocks accordingly and shield the uncertainties occurring to the estimated market coverage due to declining customer values for the new products. As is common, the new products are susceptible to such value shocks in view of the companies' own product line strategy.

\section{Speed of clearance sales and customer value}

It is also possible for a firm to penetrate in the market faster and outperform the close competing products that exist, if the ex-factory market dynamics is comparatively faster. We may determine such dynamics as escape velocity for the new products, which manifests in increasing customer value, market coverage, just-in-time supply management, augmenting product performance through in-store and 
point-of-sales demonstrations. It is observed that faster the market penetration of new products, higher is the opportunity of market coverage over the competing product in a given time and territory. The new product attractiveness may comprise the product features including improved attributes, use of advance technology, innovativeness, extended product applications, brand augmentation, perceived use value, competitive advantages, corporate image, product advertisements, sales and services policies associated therewith that contribute in building sustainable customer values towards making buying decisions on the fashion apparel in the clearance sales. The introduction of new fashion products makes it important for marketers to understand how innovators or first adopters respond to persuasion cues. It has been observed in a study that the innovativeness and perceived product newness that are one of the constituents of new product attractiveness were independent constructs that had independent effects on customer's attitude toward the brand and purchase intent for the new product. ${ }^{32}$ The attractiveness of new products is one of the key factors affecting the decision making of customers and in turn is related to market growth and sales. The higher the positive reactions of the customers towards the new products in view of their attractiveness, higher the growth in sales and so in market.

Let us assume that the product attractiveness is $F_{x}$ and initial product market investment is $M_{t}^{\left(i_{1}+i_{2}+i_{3}+\ldots i_{n}\right) j}$, perceived customer value of the new product is $V_{n p}$ and competitive advantage driver for the customer is $C_{a t}$ at a given time.

$$
F_{x}=\sum_{t}^{j h}\left[M_{t}^{\left(i_{1}+i_{2}+\ldots i_{n}\right) j}\right]\left(V_{n p}\right)\left(C_{a t}\right)
$$

Hence,

$$
F_{x}=M_{t}^{i_{n}, j} \frac{\partial v^{\prime}}{\partial t}=M_{t}^{i_{n}, j} \frac{\partial b^{\prime}}{\partial s} \frac{\partial s}{\partial t}=M_{t}^{i_{n}, j} \frac{\partial v}{\partial s}\left(V_{n p}\right)\left(C_{a t}\right)
$$

where $M_{t}^{i_{n}, j}$ denotes the initial investment made by the firm for introducing $t$ the new products, $v^{\prime}$ represents the volume of penetration of fashion apparel in a given market in time $t$ with estimated market coverage $s$. In the equation, $b^{\prime}$ expresses the volume of repeat buying during the period, the new product has been penetrated in the market by the firm. The total quality for fashion apparel in the clearance sales goes up due to the economy of scale as the quality is also increased simultaneously $\left(\partial_{v} / \partial_{s}>0\right)$ and $\left(\partial_{b} / \partial_{s}>0\right)$. In reference to the new products $x$, the competitive products create lower values to the customers $\left(\partial_{v} / \partial_{x}<0\right)$ while the innovative products irrespective of price advantages, enhance the customer value $\left(\partial_{v} / \partial_{x}>0\right)$. The value addition in the competitive products provides lesser enhancement in customer satisfaction as compared to ageing fashion products if the new fashion designs have set for faster penetration, re-buying attributes and market coverage.

Therefore

$$
\int s \partial s=\int V_{n p}+C_{a t}
$$


In the above equation, $V_{n p}$ denotes the customer value for the fashion apparel and $C_{a t}$ represents for the competitive advantage at a given time.

The prospect theory ${ }^{15}$ proposes that the intensity of gains plays strategic role in value enhancement as $G_{x t}=g_{p t}\left(\partial_{x} / \partial_{p}\right)$. In this situation, $t$ represents the period wherein the promotional strategies were implemented to enhance the customer values in reference to productspecific gains $\left(g_{p t}\right)$. In order to measure relationship/variability between the repeat buying behaviour and customer value, however, it would be appropriate to determine the cumulative decision weights $(w)$ and substituting it in the equations (1), (4) and (5), that may reveal as:

$$
G_{x t}=w \sum_{k=1}^{j h}\left[g_{p t}\left(r_{j} m_{j}\right)+\beta^{n+1} Q_{t}\right]
$$

The customer value, however, may be the driver function of gains on buying decision on fashion apparel and the influencing variables such as perceived use value and referrals.

\section{Aggregate returns on customer value}

Measuring the overall value acquired by the customer for the fashion apparel over time, in competitive products market is a complex issue. The customer value, however, may be measured in phases of the new products movement in the given market at the given time. It is necessary to define the product attractiveness stage in the market for new product overtime in reference to volume of buying and market coverage $\left(\partial v^{\prime} / \partial s\right)$, which determines the stages of product attractiveness $\left(x_{0}, x_{1}, x_{2}, \ldots, x_{n-1}, x_{n}\right)$.

Let us assume that $\left(x_{0}, x_{1}, x_{2}, \ldots x_{n-1}, x_{n}\right)$ represents customer value at different stages of product attractiveness, increasing with reference to the derived advantage from the competing product in a given market at a given time $(t)$. In the process of enhancing the customer value for the new products, a firm may use intensive customer value for fashion products; a firm may use intensive customer relationship management (CRM) strategies simultaneously to the competitive sales and marketing strategies. The integrated impact of CRM, sales and marketing strategies at different stages of product attractiveness would contribute to the customer value. Such an aggregated customer value represented by $R_{n}$, which can be calculated with the following operation:

$$
A\left(R_{n}\right)=f\left(x_{0}\right) \Delta x+f\left(x_{1}\right) \Delta x+f\left(x_{2}\right) \Delta x+\ldots .+f\left(x_{n-1}\right) \Delta x
$$

Further simplifying this equation, we get,

$$
A(R)=A\left(R_{n}\right) \lim n \rightarrow \infty+\sum_{k m}^{j m}\left[\left(\Delta v^{\prime}+\Delta b^{\prime}\right)(\Delta s)\right]^{t}
$$

In the above equation, $A(R)$ represents the aggregate returns on the customer value derived at various stages of product attractiveness and quantitative changes in the volume of goods positioned by the retail stores, repeat buying, and market coverage in terms of changes in the market shares of the firms. The aggregate returns on the customer values 
may be measured by a firm for not only the existing products in the market but also for the new products in the potential markets $A\left(R_{n}\right)_{\lim n \rightarrow \infty}$. The number of customers attracted towards promotion of fashion apperal, influence of referrals and augmented perceived use values derived by the customers may be the major factors contributing in determining the potential markets for the new products. A firm may, however, identify the potential markets in reference to its new products and market expansion policies. Besides, a firm may need to compute the trend of customer value for all the products in its product line, and measure the variability in the customer values perceived for its fashion products. The customer value trend for a given product line $\left(p_{l}\right)$ may be derived through the following equation substituting equations (5) and (9).

$$
V_{p_{l}}^{t_{0}-\infty}=\sum_{k n}^{j m}\left[A\left(R+F_{x}\right)\right] \frac{\partial s}{\partial t}
$$

In the above equation the customers' value spread across the time-frame $V^{\left(t_{0}-\infty\right)}$, which represents the value spread from the time of introduction of the new product $\left(t_{0}\right)$ till the project period $\left(t^{\infty}\right)$. It may be possible that the new product of a firm may acquire a higher market share, but relative performance in reference to the products within the given product line may be comparatively lower. Under such conditions, the profit contributed by the new product of the firm may be described as

$$
Y_{t}=D_{s i}^{j}\left[F_{x}, v^{\prime}, b^{\prime}\right] \frac{\partial s}{\partial t}
$$

where $Y_{t}$ represents the profit contribution by the new product in time $t$. In the above equation, level of decision satisfaction $\left(D_{s i}^{j}\right)$ for $i$ consumer in the $j$ th store is largely driven by the product attractiveness among several contingency conditions. The volume of penetration by clearance sales is represented by $\left(v^{\prime}\right)$ and propensity of repeat buying is denoted by $\left(b^{\prime}\right)$ in equation (11).

The model explains that the value-based customer portfolios would enhance the customer value as the product efficiency viewed from the customer's perspective, that is, as a ratio of outputs (eg resale value, reliability, safety and comfort) that the customers obtain from a product relative to inputs (price and running costs) that the customers have to deliver in exchange. The derived efficiency value can be understood as the return on the customer's investment. Products offering a maximum customer value relative to all other alternatives in the market are characterised as efficient. Market partitioning is achieved endogenously by clustering products in one segment that are benchmarked by the same efficient peer(s). This ensures that only the products with a similar output-input structure are partitioned into the same sub-market. As a result, a sub-market consists of highly substitutable products. The customer values are reflected in their competitive gains, perceived use values and volume of buying and level of quintessence. If these variables do not measure significantly, there emerges the development of switching attitude among the customers. If the organisational values are low, the supplier relationship may be risk averse due to weak dissemination of values from organisation to the suppliers. 


\section{RESULTS AND ANALYSIS}

In the following section, the paper attempts to examine the impact of both decision difficulty and personal commitment to a choice option on consumers' response to clearance sales through a series of two experimental studies. The studies examine the consumer-perceived values and cognitive relationship of buying decisions with respect to clearance sale and demonstrates a positive effect of clearance sales of unfamiliar brands on decision satisfaction. The store-loyalty measure provides information on the magnitude and impact of consumer response to clearance sales, and validates the decision satisfaction measure by providing a link between the evaluative measure and behaviour. Interestingly, in each of these studies, the premise confirming the effect of clearance sales on actual behaviour (ie store loyalty) is driven by satisfaction with the decision process.

This study examines the relationship between a clearance sale (and the resultant loss of the option to choose the alternative) and consumer decision satisfaction. In addition to examining the basic negative impact of clearance sales in reference to the availability of product options and assorted brands on consumer decision satisfaction (H1), this study attempts to explore the potential moderating role of consideration of the clearance sales alternative on consumer response. Data have been collected using the guiding questions for Study $1 \mathrm{~A}$ and $1 \mathrm{~B}$ as exhibited in Appendix.

\section{Study $1 \mathrm{~A}$}

Study $1 \mathrm{~A}$ attempts to analyse the consumer preferences and factors influencing consumer response to clearance sales leading to decision satisfaction. In each of the cases described in the first study, consumers keep their preferences easy and compromising while making decisions in a clearance sale. In this way, any negative consumer response due to a clearance sale is a conservative measure of consumers' reaction emerging from the factors of low product choice, product assortment of unfamiliar brands and restrictions on returnablility of the product.

\section{Study design}

Study $1 \mathrm{~A}$ is a $2 \times 2$ full factorial between-subject design. The first factor is the availability of choice of goods in the clearance sale affecting the buying decisions of consumers. The second factor is whether the clearance sale offer creates the store loyalty. The cover story for the experiment was that a self-service store of specialised commodities, viz. Suburbia in Mexico announces the clearance sales of fashion apparel and strategically aimed at augmenting the store-brand-loyalty from all segments of consumers. Data have been collected inviting 64 respondents to participate in this study who had positive and negative preferences towards making buying decisions in the clearance sales. The respondents were parents and relatives of the undergraduate students studying the course on international marketing during the spring and fall semesters of 2005. Participants were presented initially with a booklet that contained the introduction and focus of the study as outlined above, with a disclaimer stating that 'due to limits on sample quantities, all 
formulations may not be available to all participants'. Participants also received a description of the alternatives and their ratings on each attribute associated with the product preferences, value perceptions, store loyalty and the like. Participants were classified into three categories (C1, C2 and C3) considering four different decision attributes - price, brand association, choice of goods and days, and overall store loyalty in buying goods in the clearance sales. This process led to three principal clusters of respondents as stated below:

Cluster $C_{l}$ : Consumers, who recognise positive influence of the low price offers irrespective of brand, choice of goods or perceived value in buying of unfamiliar brands when offered in the clearance sales.

Cluster $C_{2}$ : Consumers, who recognise negative influence of the brand name or company name association in buying of unfamiliar brands, irrespective of price, choice of goods and relative advantage.

Cluster $C_{3}$ : Consumers, who just determine store loyalty as a principal attribute in making buying decisions in the clearance sales offered by a self-service store.

There are four independent variables used in the study — price, choice of goods, perceived risk and parent brand name. The dependent variable is measured as consumer perspectives on decision making towards buying goods in clearance sales of largely unfamiliar brands. The entire variable was measured by multiple items. A large number of statements have been structured to acquire the agreement or disagreement of the respondents towards their cognitive behaviour associated with the brand and company name. The statements had a seven-point scale ranging from 'fully disagree (1)' to 'completely agree (7)'. Participants were asked to place an $X$ in a box beside the formulations, which they would be most likely to consider choosing (either three or four of the six alternatives, depending on condition and instructions). Pre-testing indicated that 92 per cent of participants made these particular assortment selections in each of the three and four alternative situations.

\section{Findings}

The data collected from respondents were tested for its reliability applying the Cronbach's alpha test. Variables derived from test instruments are declared to be reliable only when they provide stable and reliable responses over a repeated administration of the test. It has been observed from the test results that the variables associated with price, choice of goods, perceived risk and parent brand name showed the highest reliability. The significance tests and clustered mean values of the selected variables have been exhibited in Table 1.

The Wilk's Lambda, a multivariate analogue of the coefficient of alienation was also tested for the major variables that derived significant 
values and upon an individual consideration of the predicators, all showed a statistically significant influence on the dependent variable except the variable denoting the expertise associated with the company that enhances the customers' satisfaction and augments their value $(p=0.128>0.05)$. The mean values on the variable segments of the clusters of respondents reveal that there is the largest gap between $C_{1}$ and $C_{2}$ on perceived risk, and a considerable separation may also be seen on perceived brand difference between the same clusters. The difference among all the three clusters $C_{1}, C_{2}$ and $C_{3}$ are, however, marginal in reference to the other two variable segments - brand and company name association and customer value enhancement. ${ }^{33}$

Satisfaction was measured with seven-point scales, first one to measure decision satisfaction and a second to measure consumption satisfaction (see Appendix for a list of the attributes). While decision satisfaction is the primary focus, it may be seen from a research study a moderate positive correlation between measures of decision and consumption satisfaction. Thus each aspect of satisfaction is measured separately, and consumption satisfaction is included as a covariate in the analyses. ${ }^{30}$ The measure of decision satisfaction (means for the four independent variables ranged from 6.41 to 6.39) yielded a Cronbach's coefficient $(\alpha)$ of 0.84 , while the measure of consumption satisfaction had $(\alpha)$ of 0.81 . The results of the analysis of covariance found the model was significant $\{\mathrm{F}(4,64)=16.6, p<0.001\}$, with an $R^{2}$ of 0.681 . Consumption satisfaction was a significant covariate $(\mathrm{F}=18.9, p<0.001)$. The main effect of consideration set membership was not significant, while the main effect for alternative availability was significant $(\mathrm{F}=13.6, p<0.01)$. More importantly, the interaction between the two terms was also significant $(\mathrm{F}=12.8, p<0.01)$. The correlation between the two factors was $r=0.36$, similar to correlations of 0.37 and 0.39 and a factor analysis of the eight items found two factors with eigen values greater than one, with the six consumption items loading highly on one factor, while the six decision items loaded highly on a second factor. Planned contrasts were performed to measure the level of decision satisfaction $\left(D_{s i}^{j}\right)$ for $i$ consumer in the $j$ th store, among several contingency conditions. As might be expected from the significant two-way interaction, the magnitude of the clearance sale effect (the difference between an available and a clearance-sale condition) varied across the consideration

Table I: Significance tests and clustered mean values of the variables under study

\begin{tabular}{|c|c|c|c|c|c|}
\hline \multirow[t]{2}{*}{ Variable segments } & \multirow[t]{2}{*}{$\operatorname{Cronbach}(\alpha)$} & \multirow[t]{2}{*}{ Wilk's $(\lambda)^{*}$} & \multicolumn{3}{|c|}{ Clusters' means } \\
\hline & & & $c_{1}$ & $\mathbf{C}_{2}$ & $\mathrm{C}_{3}$ \\
\hline$V_{1}$ Price advantage in Clearance Sales & 0.835 & $0.736(0.201)^{+}$ & 4.97 & 6.12 & 5.82 \\
\hline $\begin{array}{l}V_{2} \text { Choice of goods and risk perceived by the } \\
\text { customers }\end{array}$ & 0.795 & $0.927(0.163)^{+}$ & 5.71 & 7.52 & 6.24 \\
\hline$V_{3}$ Brand and company name association & 0.847 & $0.984(0.233)^{+}$ & 4.43 & 5.84 & 5.69 \\
\hline $\begin{array}{l}V_{4} \text { Customer value enhancement through } \\
\text { store- loyalty }\end{array}$ & 0.645 & $0.938(0.128)^{++}$ & 4.05 & 4.68 & 5.14 \\
\hline
\end{tabular}

*Figures in parentheses represent $p$-values

${ }^{+} p=>0.01$ and ${ }^{++} p=>0.05$ 
set conditions. Essentially, the negative clearance sale effect was significant only in conditions in which the clearance sale was a member of the participant's consideration set. A contrast between (i) the inconsideration set and available condition (mean $\left.\left(D_{s i}^{j}\right)=8.01\right)$ and (ii) the in-consideration set and discount sales condition $\left(\left(D_{s i}^{j}\right)=7.64\right)$ demonstrated a significant difference $(\mathrm{F}=19.3, p<0.001)$, while a contrast between (i) the not-in-consideration set and available condition $\left(\left(D_{s i}^{j}\right)=9.27\right)$ and the (ii) not-in-consideration set and discount sales condition $\left(\left(D_{S i}^{j}\right)=9.77\right)$ was not statistically significant $(\mathrm{F}<1)$.

\section{Study 1B}

A duplication of Study 1A was also performed, with the addition of a personalised clearance sale condition in which participants received a clearance sale announcement that was targeted more directly towards them while providing further opportunity to examine $\mathbf{H 1}$ and $\mathbf{H 3}$.

\section{Study design}

Study $1 \mathrm{~B}$ is a 2 (inclusion or exclusion of the described alternative in the consideration set) $\times 3$ (clearance sale announcement: none/impersonal/ personal) between-subject design. The procedure is very similar to that employed in Study 1A with a few minor modifications. In this study, participants were also asked to attempt to guess the purpose of the study. Data have been collected inviting 87 respondents to participate in this study who had positive and negative preferences towards making buying decisions in the clearance sales. The respondents were parents of the undergraduate students studying the course on international marketing during the spring and fall semesters of 2005. During this experimental study, participants were served with a note that read: 'All alternatives are available at this time'. Participants in the impersonal constraint conditions received a note stating that in this study Cluster $C_{2}$ is eliminated and brand loyalty is held high as in exclusive store like Christian Dior for its fashion apparel.

\section{Findings}

Cronbach's coefficient $(\alpha)$ of 0.78 for decision and 0.86 for consumption satisfaction were obtained for decision satisfaction measures. Similar factor analysis results to Study 1A were observed. Sample sizes, means and standard deviations for each of the six conditions on the composite decision satisfaction measure are shown in Table 1. In addition to the consumption satisfaction covariate, two categorical variables were included in the analysis of variance as class variables: consideration set membership (in/out) and a form of clearance sale announcement (none/ impersonal clearance sale announcement/personal clearance sale announcement). The overall model was significant $(\mathrm{F}(4,87)=7.6$, $p<0.0001)$, as was the covariate consumption satisfaction $(\mathrm{F}=7.4$, $p<0.001)$. The main effect of the presence or form of clearance sale announcement was significant $(\mathrm{F}=6.6, p<0.001)$, as was the main effect of consideration set membership $(\mathrm{F}=4.3, p<0.05)$. As in Study 1A, the interaction between the two terms was significant $(\mathrm{F}=4.8, p<0.05)$. 
Two planned contrasts were run for both the self-reference conditions and the nonself-reference conditions. The nonself-reference conditions are influenced by the word of mouth, referral interactions and psychodynamics at the point of sales. The first contrast between (i) the self-reference conditions and available announcement of store-based clearance sales $\left(\left(D_{s i}^{j}\right)=8.27\right)$ and (ii) the nonself-reference decisions clearance sale announcement condition $\left(\left(D_{s i}^{j}\right)=6.46\right)$ demonstrated a significant difference $(\mathrm{F}=18.9, p<0.001)$. Similarly, a planned contrast between (i) the self-reference decisions and available store-based announcement condition $\left(\left(D_{s i}^{j}\right)=5.96\right)$ and (ii) the nonself-reference decisions and forced-buying decisions $\left(\left(D_{s i}^{j}\right)=5.47\right)$ also proved significant $(\mathrm{F}=6.9, p<0.05)$. Consistent with Study 1 results and with expectations, however, when these two planned contrasts were run for the consumer decision process sets no significant differences were found. The Eigen values have been computed to estimate the shared variance between the respective optimally weighted canonical variates of dependent and independent variables. The canonical correlations analysis has been derived considering the set of dependent and independent variables representing the canonical functions. The analysis of the data indicates that the first function $\left(F_{1}\right)$ has the highest eigenvalue $(0.539)$, which accounts for 89.36 per cent while the second function $\left(F_{2}\right)$ has shown relatively smaller eigenvalue $(0.152)$ with 11.64 per cent of the explained variance. The analysis reveals that the canonical correlations for $F_{1}$ and $F_{2}$ are 0.637 and 0.174 , respectively. Accordingly, it may be stated that the $F_{1}$ is superior to $F_{2}$. Table 2 exhibits the standardised canonical coefficients of discriminate functions and functions at group centroids.

The results show that the value of coefficients among the variable segments $V_{1}$ and $V_{2}$ are of higher degree for canonical function $F_{1}$, which describes that these two variables, perceived risk and perceived brand difference, are basically associated with the function. Similarly, the company name and customer value variables are associated with the function $F_{2}$ as the coefficients show relatively higher values. In reference to the clusters of respondents, the segment $C_{1}$ that represents positive influence of brand name in consumers' behaviour of respondents shows the highest value on function $F_{1}$, while $C_{2}$ represents the lowest value as the function $F_{1}$ is associated with perceived risk and perceived brand difference variables.

\section{Discussion on Study $1 A$ and $1 B$}

The results of both Study 1A and 1B provide strong support for H1, H2 and H3. As predicted, a clearance sale of a low choice alternative of goods led to a negative consumer response. In addition, the clearance sale impact on decision satisfaction was evidenced by the significant interaction between self-reference and externally motivated criterion in both the studies. These results support the contention that consumer response to clearance sales is moderated by price and nonprice factors. Both types of decision satisfaction process of consumers led to support the consumption behaviour in the clearance sales significantly and show the extent of influence that makes the consumers committed to a 
Table 2: Canonical values and fit of the model

\begin{tabular}{|c|c|c|c|c|c|c|c|}
\hline \multirow{2}{*}{$\begin{array}{l}\text { Canonical } \\
\text { functions }\end{array}$} & \multicolumn{4}{|c|}{ Variable segments } & \multicolumn{3}{|c|}{ Respondent clusters } \\
\hline & $v_{1}$ & $v_{2}$ & $v_{3}$ & $v_{4}$ & $c_{1}$ & $C_{2}$ & $C_{3}$ \\
\hline$F_{1}$ & 0.837 & 0.577 & 0.061 & 0.316 & 0.874 & -0.152 & -0.0249 \\
\hline $\mathrm{F}_{2}$ & -0.173 & 0.264 & 0.326 & 0.632 & 0.114 & 0.227 & -0.106 \\
\hline
\end{tabular}

particular discount sales outlet. This process dynamics supports the storebrand-loyalty of consumers towards going for a clearance sale. In both the components of Study 1, consumer response to clearance sale is found to be positive.

\section{LIMITATIONS OF THE STUDY}

The most important limit relates to the interpretation of the store-loyalty data and their relationship to clearance sales. Thus, the magnitude of the observed behavioural responses to clearance sales may represent the upper end of consumer response. This assumption is not entirely unrealistic, as consumers are often under time pressure or are in geographically constrained situations that require immediate choice. As has been suggested by previous research, ${ }^{34}$ consumers, however, often decide not to choose in response to a clearance sale situation. Assuming that a clearance sale is a cyclical phenomenon with the self-service stores, the issue of managing the customer value may be one of the significant areas, which may provide some interesting opportunities for future research. Despite methodological and relational limitations, the current research might have provided a new direction for exploring many research questions ahead.

\section{CONCLUSIONS}

The behaviour towards the clearance sales has been discussed in a series of studies in reference to consumer personality traits resulting in significantly different levels of decision satisfaction. Consumers exposed to a clearance sale are substantially more likely to return to the same store on their next shopping trip. The magnitude of the shift in store-loyalty behaviour magnifies just how powerful an impact a clearance sale can have on a consumer's purchase experience. The findings of the study indicate that clearance sales lead to substantial consumer response in a number of different choice contexts. Response to a clearance sale was found to be a function of two primary forces - the degree to which a consumer was personally committed to the discount sales alternative and changes in the difficulty of making a decision due to limitation of buying options. In all, the results of the two studies demonstrate that consumers' response to clearance sales, both in terms of decision satisfaction levels and observed store-loyalty behaviour, are strongly influenced by the variables of price sensitivity, attractiveness of products, store loyalty and perceived value on available brands. While consumption satisfaction was significantly related to decision satisfaction evaluations, it was not 
itself directly affected by any of the clearance sale manipulations. The results clearly show that clearance sales affect consumers' decision experience to some extent, but not their consumption experience. Further, the effect on the consumers' decision experience is strong enough to be evidenced in subsequent store choice decisions. In clearance sales offered by the self-service stores, the trade-offs, however, must be made between the breadth of product assortment and the store's ability to maintain adequate levels of inventory for each of the products and brands the store decides to include in the offer. The study revealed that high perceived risk and brand difference induce the consumers to review the brand name in the process of making buying decisions. The framework for measuring the customer values discussed in this paper provides analytical dimensions for establishing the customer relationship by the firm and to optimise its profit levels by gaining the competitive advantage in the short run.

\section{Acknowledgements}

This paper has been developed out of the research project on 'Building Customer Values and Brand through Advertising by the Multinational Discount Retail Chain Stores' officially sanctioned to the author during 2004-2005. The author expresses his thanks to the Director, CIGEO Department and Dr. Jorge H Leon Pardo, Director of Department of Marketing, ITESM, Mexico City Campus for providing administrative support in conducting this study. The author sincerely acknowledges also the support provided by Amritanshu Rajagopal, under-graduate student of Industrial and Systems Engineering of ITESM, Mexico City Campus in computing the data and developing tables in this paper.

\section{References}

1. Hess, J.D. \& Eitan, G. (1987). Loss leader pricing and rain check policy. Marketing Science. 6, 358-374.

2. Lazear, E.P. (1986). Retail pricing and clearance sales. The American Economic Review. 76, 14-32.

3. Schary, P.B. \& Martin, C. (1979). The anatomy of a clearance sale. Journal of Retailing. 55, 59-70.

4. Rajagopal (2005). Measuring variability factors in consumer values for profit optimization in a firm - A framework for analysis. Journal of Economics and Management. 1, 85-103.

5. Forbes (1999). Santa Flaws December 27.

6. Morschett, D., Swoboda, B. \& Foscht, T. (2005). Perception of store attributes and overall attitude towards grocery retailers: The role of shopping motives. The International Review of Retail, Distribution and Consumer Research. 15, 423-447.

7. Babakus, E., Bienstock, C.C. \& Van Scotter, J.R. (2004). Linking perceived quality and customer satisfaction to store traffic and revenue growth. Decision Sciences. 35, 713-737.

8. Konishi, H. (1999). Concentration of competing retail stores, Boston College, Working Papers in Economics, No. 447

9. Pratkanis, A.R \& Peter, H.F. (1992). A brief history of research on phantom alternatives: Evidence for seven empirical generalizations about phantoms. Basic and Applied Social Psychology. 13, 103-122.

10. Luce, R.D. (1959). Individual Choice Behaviour: A Theoretical Analysis, Wiley, New York.

11. Merrilees, B. \& Fam, K.S. (1999). Effective methods of managing retail sales. The International Review of Retail, Distribution and Consumer Research. 9, 81-92.

12. Han, S., Gupta, S. \& Lehmann, D.R. (2001). Consumer price sensitivity and price thresholds. Journal of Retailing. 77, 435-456.

13. Tversky, A. \& Eldar, S. (1992). Choice under conflict: The dynamics of deferred decision. Psychological Science. 3, 358-361.

14. Dhar, R. (1997). Consumer preference for a no-choice option. Journal of Consumer Research. 24, 215-231.

15. Tversky, A. \& Kahnman, D. (1981). The framing decisions and psychology of choice. Science. 211, 453-458.

16. Guadagni, P.M. \& John, D.C.L. (1983). A logit model of brand choice calibrated on scanner data. Marketing Science. 2, 203-238. 
17. Wakefield, K.L. \& Inman, J.J. (2003). Situational price sensitivity: The role of consumption occasion, social context and income. Journal of Retailing. 79, 199-212.

18. Gourville, J.T. \& Koehler, J.J. (2004). Downsizing price increases: A greater sensitivity to price than quantity in consumer markets, HBS Marketing Research Paper No. 04-01, January.

19. Lawrence, D. (2004). Measuring the pulling power of promotions. Young Consumers: Insights and Ideas for Responsible Marketers. 6, 50-53.

20. Reichheld, F.F. \& Sasser, W.E. (1990). Zero defections: Quality comes to services. Harvard Business Review. 68, 105-111.

21. Ganesh, J., Arnold, M.J. \& Reynolds, K.E. (2000). Understanding the customer base of service providers: An examination of the difference between switchers and stayers. Journal of Marketing. 64, 65-87.

22. Epstein, G.S. (1998). Retail pricing and clearance sales: The multiple product case. Journal of Economics and Business. 50, 551-563.

23. Hammock, T. \& Jack, W.B. (1966). The attractiveness of choice alternatives when freedom to choose is eliminated by a social agent. Journal of Personality. 34, 546-553.

24. Ndubisi, N.O. \& Moi, C.T. (2005). Customer behavioural responses to sales promotion: The role of fear of losing. Asia Pacific Journal of Marketing and Logistics. 17, 32-49.

25. Gilbert, D.C. \& Jackaria, N. (2002). The efficacy of sales promotion in uk supermarkets: A customer view. International Journal of Retail and Distribution Management. 30, 315-327.

26. Westbrook, R.A., Joseph, W.N. \& James, R.T. (1978). Satisfaction/dissatisfaction in the purchase decision process. Journal of Marketing. 42, 54-60.

27. Oakley, P. (1996). High tech NPD success through faster overseas launch. European Journal of Marketing. 30, 75-91.

28. Hallowell, R. (1996). The relationships of customer satisfaction, customer loyalty, and profitability: An empirical study. International Journal of Service Industry Management. 7(4), $27-42$.

29. Gale, B.T. (1997). Satisfaction is not enough. Marketing News. 32(21), 18.

30. Fitzsimons, G.J., Eric, A.G. \& Donald, R.L. (1997). Decision and consumption satisfaction: Implications for channel relation Marketing Studies Centre Working Paper Series. No. 313, University of California, Los Angeles.

31. Steenkamp, J.E.M. \& Gielens, K. (2003). Consumers and market drivers of trial probability of new consumer packaged goods. Journal of Consumer Research. 30, 368-384.

32. Lafferty, B.A. \& Goldsmith, R.E. (2004). How influential are corporate credibility and endorser attractiveness when innovators react to advertisement for a new high technology product? Corporate Reputation Review. 7, 24-26.

33. Rajagopal (2007). Influence of brand name in variety seeking behaviour of consumers: An empirical study. International Journal of Management Practice. 2(4), 306-323.

34. Greenleaf, E.A. \& Donald, R.L. (1995). Reasons for substantial delay in consumer decision making. Journal of Consumer Research. 22, 186-199.

\section{Appendix A}

\section{Core questions}

Common Scale 1 = strongly agree, $7=$ strongly disagree

1. I have low choice in the clearance sales than expected.

2. Given the alternatives to choose from the known brands in regular sales, I would prefer to buy in the clearance sales being sensitive to the price.

3. What is the level of satisfaction with the product you chose? (Scale $1=$ extremely satisfied, $7=$ extremely dissatisfied).

4. I am very displeased with the product I purchased in the clearance sale.

5. I am very happy with the product I purchased in the clearance sale.

6. The choice of goods I bought is similar to my ideal choice.

7. I found the process of deciding which product to buy frustrating in clearance sale. 
8. Several good options were available for me to choose in the market but I preferred to be store loyal.

9. How satisfied or dissatisfied are you with your experience of making a buying decision of unfamiliar brands offered on discount in the clearance? (Scale 1=extremely satisfied, $7=$ extremely dissatisfied).

10. I thought the choice selection was good.

11. I would be happy to buy goods in the clearance sales repeatedly.

12. I found the process of deciding which product to buy in the clearance sale an interesting experience. 